These are non-specific features and are present in the Prader-Willi syndrome (PWS) and many other conditions. The authors themselves state that their patients lack the typical features of PWS, which are low birth weight, neonatal hypotonia, narrow bifrontal diameter, hypogonadism, short stature, and feeding problems during the first year of life followed by hyperphagia and obesity in early childhood. In contrast, patients 1 to 7 developed severe obesity between the ages of 5 and 10 years without change in diet. None of the patients fulfils the diagnostic criteria described by Holm et al.

Although we agree that obese and mentally retarded boys should be tested for the fragile $X$ syndrome, we feel that this phenotype should no be described as "Prader-Willi-like". This description is misleading and confusing, because all of the typical features of PWS are absent in the patients described by de Vries et al. ${ }^{1}$ Careful use of the terms "Prader-Willi syndrome" and "PraderWilli-like" is important, because the syndrome is overdiagnosed by geneticists and paediatrician who are not familiar with the specific features of PWS. Although PWS can be rapidly tested for at the DNA level, ${ }^{3}$ careful clinical distinction of this syndrome from other conditions is necessary.

In conclusion, we suggest that obesity should be included as an important feature in the fragile $X$ syndrome and the term "Prader-Willi-like" should be avoided.

GABRIELE GILLESSEN-KAESBACH BERNHARD HORSTHEMKE Institut für Humangenetik, Universitätsklinikum Essen, Hufelandstrasse 55, D-45122 Essen

Germany.

1 de Vries BBA, Fryns JP, Butler MG, et al. Clinical and molecular studies in fragile $(\mathrm{X})$ patients with a Prader-Willi-like phenotype. $f$ patients with a Prader-Wili

2 Holm VA, Cassidy SB, Butler MG, et al. PraderWilli syndrome: consensus diagnostic criteria. Pediatrics 1993;91:398-402

3 Dittrich B, Robinson W, Knoblauch $\mathrm{H}$, et al Molecular diagnosis of the Prader-Willi and Angelman syndromes by detection of parentof-origin specific DNA methylation in 15q1113. Hum Genet 1992;90:313-15.

\section{Genetic studies of thymic carcinoids in multiple endocrine neoplasia type 1}

Multiple endocrine neoplasia type 1 (MEN1) is an autosomal dominant disease characterised by hyperplasia or neoplasia of the parathyroids, anterior pituitary, and the endocrine pancreas. ${ }^{1}$ Other associated features, such as asymptomatic adrenal neoplasia, thyroid nodules, carcinoid tumours, lipomas, and pinealomas, have been reported at a much lower frequency. ${ }^{2}$ The age of presentation can range from early teens to late fifties. To date, only a few MEN1 related thymic carcinoids have been described. In the largest reported MEN1 family, ${ }^{3}$ four affected males were found to have metastatic thymic carcinoids but none of the patients was immediately related. ${ }^{4}$ One malignant and one benign case were reported in a kindred of German extraction ${ }^{5}$ and one case each in two kinships from Canada. ${ }^{6}$

The gene responsible for MEN1 was firs mapped to chromosome $11 \mathrm{q} 13^{7}$ and subsequently predictive testing using RFLP markers was developed. ${ }^{8}$ The two commonest MEN1 lesions, parathyroid and endocrine pancreatic neoplasia and their sporadic counterparts, have been shown to have loss of heterozygosity in the MEN1 region suggesting that the putative MEN1 gene is a tumour suppressor gene ${ }^{79-11}$ To date, only one bronchial carcinoid from a MEN1 patient has been studied but no loss of heterozygosity was found in the MEN1 genomic region. ${ }^{12}$ Thymic carcinoids, on the other hand, whether sporadic or familial, have never been studied at the molecular level.

We report here five affected sibs from a Tasmanian MEN1 family (Tasman family 2), of whom two were found to have malignant thymic carcinoids. Despite exhaustive genealogy study extending back to the first generation of this kindred in Tasmania, no consanguineous link can be established between this family and the largest reported MEN1 family in Tasmania. ${ }^{3}$ Furthermore, the mother of five affected sibs, who died of metastatic glucagonoma, was found to be the oldest member affected (figure)

The aims of this study were to determine the region of genetic linkage in Tasman family 2 and thus the feasibility of using MEN1 linked markers for predictive testing in this family, and to elucidate the genetic defects of MEN1 related thymic carcinoids.

Subject II.1 was admitted for surgery for primary hyperparathyroidism. Preoperative chest $x$ ray showed a shadow in the anterior mediastinum and CT scan identified a tumour mass arising in the thymus. An infiltrating mass of tumour and metastatic lymph node could not be dissected from the great vessels but were biopsied. Malignant thymic carcinoid was confirmed histologically. Patient II.5 had a history of insulinoma and multiple lipomat and was found to have hypercalcaemia. CT scan showed a tumour in the anterior mediastinum arising from the thymus. Again a mass of tumour and lymph node extending around and infiltrating the great vessels was inoperable but was biopsied and malignant thymic carcinoid was confirmed. The other three sibs (II.3, II.7, II.9) and four children of the next generation (III.2, III.4, III.9, III.12) were all found to have hyperplastic parathyroid glands and an insulinoma was removed in addition from III.2. Lymphoblastoid cell lines were established from 24 family members.

Eleven DNA probes previously shown to be linked to the MEN1 locus, ${ }^{8}$ spanning $14 \%$ meiotic recombination, were used. DNA from the cell lines and tumours was extracted, digested to completion with appropriate restriction enzymes, electrophoresed, blotted onto nylon membranes, an hybridised to radiolabelled probes as previously described. ${ }^{13}$ Linkage was analysed using the program LIPED with the criteria for scoring the disease state as described previously. ${ }^{8}$ Two malig nant thymic carcinoids (II.1, II.5), five hyperplastic parathyroid glands (II.1, II.5, II.9, III.2, III.12), and one pancreatic tumour (III.2) were studied for loss of heterozygosity.
In linkage analysis, two markers, CL15 and CLGW4, were uninformative in the pedigree. Meiotic recombinants were detected for markers telomeric of D11S427 (INT2 and D11S97), so negative lod scores $(-2.80$ in both cases) were obtained for these markers. However, peak positive lod scores were obtained at a recombination fraction of 0 for each of the other markers, ranging from 0.21 (CD20) to 1.85 (D11S149/D11S288), thus supporting linkage of this family to the MEN locus at $11 \mathrm{q} 13$ (results not shown). Genotypes of the family members are shown in the figure. In the youngest generation, four are evidently affected but the other 11, despite negative findings in biochemical and radiological screenings, were labelled as "unknown" as all were below 35 years of age. ${ }^{7}$ One of these "unknown" cases (III.6) was found to have inherited the mutant (hatched) chromosome and thus requires repeated follow up to detect early signs of disease.

The insulinoma (III.2) and one hyperplastic parathyroid gland (II.9) showed loss of heterozyg osity for all informative markers from D11S288 D11S149 to INT2 (results not shown). In all cases the loss involved the allele derived from the unaffected parent, that is, the putative wild type allele. The other four hyperplastic parathyroid glands and two malignant thymic carcinoids did not show any loss of heterozygosity in the MEN1 region. Al though minute somatic deletions or point mutations, undetectable by the current method, canno be excluded, this finding, together with the lowe incidence of thymic carcinoids in MEN1 patients, suggests that the genetic trigger for their tumorigenesis might be different from that of the common MEN1 related tumours. Further studies in delineating specific genetic mutations in thymic tumours are required.

This work was supported by grants from the Tasmanian Cancer Committee, Queensland Cance manian Cancer Committee, Queensland Cancer Foundation, Swedish Cancer Foundation, Swedish Medical Research Council, and the Magnus BergMedical Research Council, and the Magnus Berg-
well Foundation. We would like to thank Dr John well Foundation. We would like to thank Dr John of the family members for their kind cooperation.

BIN T TEH* NICHOLAS K HAYWARD MARILYN $\mathrm{K}$ WALTERS, Queensland Cancer Fund Research Unit foint Experimental Oncology Program, foint Experimental Oncology Program,
Queensland Intitute of Medical Research, Herston 4029, Australia. HOSEPH $\mathrm{H}$ SHEPHERD STEPHEN WILKINSON Department of Surgery, Department of Surgery,
University of Tasmania, University of Tasmania MAGNUS NORDENSKJOLD CATHARINA LARSSON Department of Clinical Genetics, Karolinska Institute

S-10401 Stockholm, Sweden.

*Present address: Department of Diabetes and Endocrinology, Princess Alexandra Hospital, Woollongabba 4102, Queensland, Australia.

1 Wermer P. Endocrine adenomatosis and peptic ulcer in a large kindred. $A m \quad \mathcal{M e d}$ 1963;35:205-12.

II

III

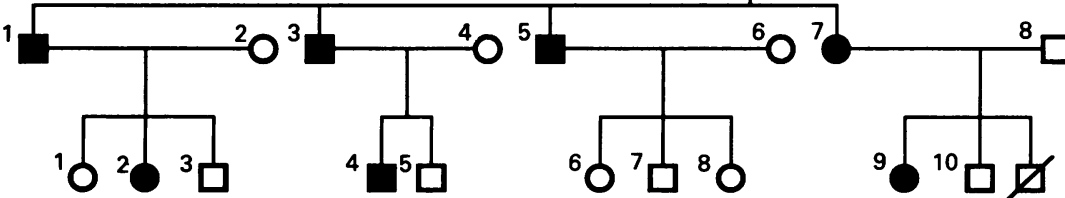

9 ${ }^{3} \square$
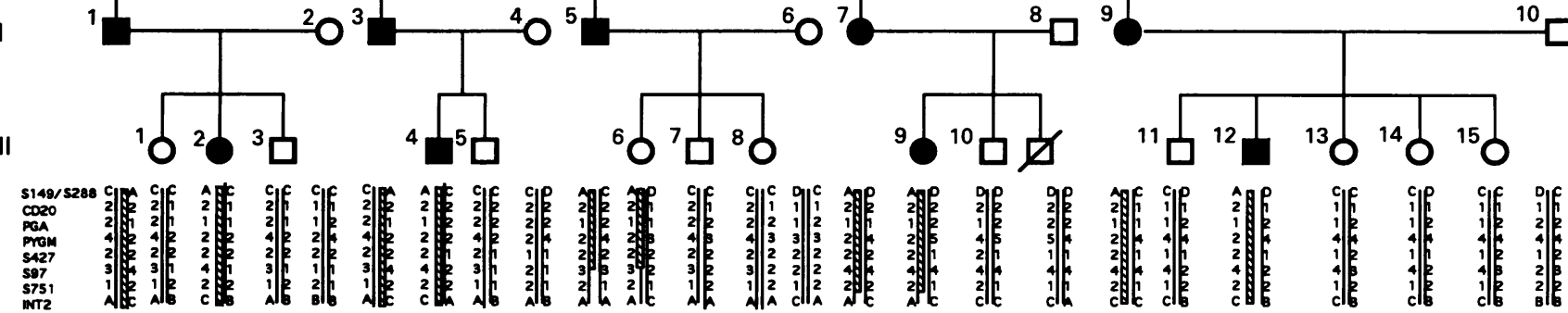

Pedigree of Tasman family 2 showing segregation of chromosome haplotypes for the marker systems which are listed on the left. The chromosome carrying the mutant allele (hatched line) has been inherited by subject III.6, illustrating the usefulness of linkage studies in presymptomatic testing for MEN1. Meiotic crossovers, indicated by thin lines extending from the hatched lines, occurred in II.5, II.7, III.6, and III.9. 
2 Brandi ML, Marx SJ, Aurbach GD, Fitzpatrick LA. Familial multiple endocrine neoplasia type 1: a new look at pathophysiology. Endocrinol Rev 1987;8:391-405.

3 Shepherd JJ. The natural history of multiple endocrine neoplasia type 1. Arch Surg 1991;126:935-52.

4 Wilkinson S, Teh BT, Davey KR, McArdle JP, Young M, Shepherd JJ. Cause of death in Young M, Shepherd JJ. Cause of

5 Marx SJ, Vinik AI, Santen RJ, Floyd JC, Mills JL, Green J. Multiple endocrine neoplasm JL, Green J. Multiple endocrine neoplasm type 1 : assessment of laboratory tests to screen
for the gene in a large kindred. Medicine for the gene in

6 Farid NR, Buehler S, Russell NA, Maroun FB, Allderdice P, Smyth HS. Prolactinomas in familial multiple endocrine neoplasia syndrome type 1: relationship in HLA and carcinoid tumors. Am f Med 1980;69:874-80.

7 Larsson C, Skogseid B, Oberg K, Nakamura Y Nordenskjold M. Multiple endocrine neoplasia type 1 gene maps to chromosome 11 and is lost in insulinoma. Nature 1988;332:85-7.

8 Larsson C, Shepherd J, Nakamura Y, et al. Predictive testing for multiple endocrin 7 Clin Invest 1992;89:1344-8.

9 Friedman $\mathrm{E}$, Sakaguchi $\mathrm{K}$, Bale $\mathrm{AE}$ et al Clonatity of multiple endocrine heoplasia type 1 . $N$ Engl $f$ Med 1989;321:213-8.

10 Bystrom C, Larsson C, Blomberg C, et al. Localization of the gene for multiple endoLocalization of the gene for multiple endo-
crine neoplasia type 1 to a small region within chromosome $11 \mathrm{q} 13$ by deletion mapping in tumours. Proc Natl Acad Sci USA 1987;87:1968-72.

11 Sawicki MP, Wan YY, Johnson C, Berenson J, Gatti R, Passaro E. Loss of heterozygosity on chromosome 11 in sporadic gastrinomas. Hum Genet 1992;89:445-9.

12 Bale AE, Norton JA, Wong EL, et al. Allelic loss on chromosome 11 in hereditary and sporadic tumors related to familial multiple endocrine neoplasia type 1. Cancer Res 1991;51:1154-7.

13 Larsson C, Weber G, Kvanta E, et al. Isolation and mapping of cosmid clones revealing RFLPs around the MEN1 locus. Hum Genet 1992;89:187-93.

\section{BOOK REVIEWS}

If you wish to order or require further information regarding the titles reviewed here, please write to or telephone the BMJ Bookshop, PO Box 295, London WC1H 9JR. Tel 071383 6244. Fax 071383 6662. Books are supplied post free in the UK and for BFPO addresses. Overseas customers should add $15 \%$ for postage and packing. Payment can be made by cheque in sterling drawn on a UK bank or by credit card (Mastercard, Visa, or American Express) stating card number, expiry date, and full name. (The price and availability are occasionally subject to revision by the Publishers.)

Advances in Human Genetics. Volume 21. Ed H Harris, K Hirschhorn. (Pp 465; \$89.50.) New York: Plenum Press. 1993.

Each year since 1970 a new volume of $A d$ vances in Human Genetics has appeared, edited every year by Harry Harris and Kurt Hirschhorn and every year containing five reviews. It must be difficult picking topics which are interesting but not too fast moving for the inevitable slow book production process. Four of the five articles in this volume have suffered to some degree from important advances coming too late to include. Moser's chapter on peroxisomal disorders missed the identification of the gene for $\mathrm{X}$ linked adreno- leucodystrophy. Jennifer Puck (X linked immunodeficiencies) writes that none of the genes, apart from that for chronic granulomatous disease, has been cloned. Goddard and Solomon (Genetic aspects of cancer) discuss oncogenes and tumour suppressor genes but not microsatellite instability. Zannis, Kardassis, and Zanni discuss mutations affecting lipoproteins, but only in connection with heart disease. The fifth chapter is by Grabowski on Gaucher disease. Each author, we are told, was given the opportunity at page proof time to write a short addendum containing the most up to date material, but only Moser took up the offer. The editorial hand was certainly not heavy. Chapters range from under 40 to almost 200 pages, and the style of references varies. Comparing Goddard and Solomon's crisp 50 page summary of Genetic aspects of cancer with Moser's 100 page review of peroxisomal disorders, both read well, but surely they are not aimed at the same audience? One audience wants an outline, the other wants details.

These books of major reviews, two to three years in gestation, are curious beasts. It's heartwarming that people of unquestionable authority are willing to put in so much time and effort for no material reward. The world must be the better for their efforts. But I wonder just how much better it is? How many people on the one hand are ready to spend a day or two digesting the detail but, on the other hand, aren't part of the personal networks by which people active in the field keep themselves informed? I'm reluctant to recommend them to students writing dissertations because most of the benefit to the student is in locating and digesting primary publications. They are good for orienting new postgraduates, with supplemental reading to bring them up to date. They would be good for summarising a field which has reached a milestone: next year would be just right for a major review of Huntington's disease (but this series had one in 1991). Do working scientists read them? Personally I find them too long and too detailed. The much shorter articles in Annual Reviews of Genetics are about my limit for general interest topics. Trends in Genetics, Nature News and Views commentaries, and Cell minireviews are my main sources for filling in necessary background.

Should you buy Advances in Human Genetics? Yes, if it contains a review you particularly want. No, if you just want to keep an adequate reference bookshelf. Looking through the contents of past volumes, if you had them all on your shelf you would not have a summary of the milestone developments in human genetics over the period. For example you would have nothing on physical mapping, on mitochondrial diseases, on microdeletions, on imprinting, on trinucleotide repeats, or, until this year, on retinoblastoma or oncogenes. Annual Reviews of Genetics does a better job of covering a wide field at a consistent level. But if you happen to want an encyclopaedic review of lipoproteins - and now that they are involved in Alzheimer's disease as well as heart disease, who doesn't? then this volume is just the ticket.

\section{ANDREW P READ}

Human Gene Mutation. D N Cooper, M Krawczak. (Pp xiv +402 ; 49.50 .) Oxford: Bios Press. 1993.

Mutation remains both the major intellectual problem in its decipherment and interpre- tation: it presents the major practical problem of the detection of mutagens and the protection of our future.

When it was assumed that loci were few and alleles few or absent, and that mutation rates were equal at all loci and from all alleles, and equal in man, mouse, and fly, the basis for the birth and death rates of mutations, and their life expectancy, were defined by Haldane, Fisher, Wright, and Muller. These firm theoretical foundations are now known to have a somewhat tenuous relation to reality. The theological concept of the ideal type, the homozygous ideal, based on God's image continued to permeate concept formation When variation occurred it was assumed that selection, rather than chance, dominated survival, and Fisher's term linkage equilibrium (now often termed linkage disequilibrium) and E B Ford's term polymorphism were defined in 1930 and 1940 to cover allelic association and common allelic variation respectively.

The realities of blood transfusion and the display of extreme variation by the starch gel showed that reality was other. The concept of neutrality, which abolished both the problem and the possibility of having evolved to discuss it, introduced a fertile mathematical diversion and showed that neutral variants only had to be sufficiently numerous for some to survive, prosper, and even expel their parental alleles.

Now at last there is a book based on raw data, discussed on a sound foundation of words, and aided but not dominated by sufficient and necessary mathematics. Not only are all varieties of mutation discussed, largely around the authors' expertise in blood and how it clots, but extensive appendices provide an anthology of all that is known to ail ou species and has been defined at the genomic level. Reading it imposes a pleasant if formidable task on the reviewer. Not only does it excel in clarity but many references, and their discussion, are remarkably recent.

In the treacherous fields of terminology and the word-number interface there are some minor problems worth comment. The diagrams, apparently based on astute use of a spreadsheet package, are very clear, numerous, and well integrated with the text. How ever, the unnecessary imposition of a third dimension in some does not assist clarity. The computer's expression of chi squared to three places of decimals needs taming Tuberous sclerosis is now largely split between loci on chromosomes 9 and 16: 11 and 12 have little support, a very recent finding. Harry Harris's operational use of "polymorphism", to cover frequencies exceeding $1 \%$, a reasonable use in the late sixties, is credited to Vogel and Motulsky 20 years later. Ford defined it unambiguously as "the occurrence together in the same locality of two or more discontinuous forms of a species in such proportions that even the rarest of them cannot be maintained merely by mutation". It is now used - or since the word is longer than the neutral term "variant" - misused - so extensively that Ford's useful term, which dominated evolutionary theory for several decades, has died with him, and it is now too late to modify its well established misuse.

Linkage analysis, another casualty of widespread misunderstanding, features as a chapter, and benefits from Clayton's advice. However, the pedigree shown does not need lods as phase is defined and deduction and counting, the appropriate method when phase is clear, are omitted. A few paragraphs on 